\title{
NOTAS
}

\section{HISPANOAMERICANO (H)ORA, (H)ORATICO}

Varios diccionarios del español de América registran una palabra hora en el sentido de 'epilepsia': Chile: hora, ora "nombre vulgar de la epilepsia, alferecía y otras enfermedades de los nervios" (Zorobabel Rodríguez, Dicc. de chilenismos, Santiago de Chile, 1875, pág. 337); Colombia: hora "epilepsia" (Leonardo TAscón, Dicc. de provincialismos y barbarismos del Valle del Cauca, Bogotá, s. a., pág. I7o) Puerto Rico y Cuba: hora "enfermedad de aves de corral, especie de epilepsia" (A. Malaret, Vocabulario de Puerto Rico, San Juan, P. R., 1937, pág. 469; y en su Diccionario de americanismos, 3a. ed., Buenos Aires, 1946, pág. 469 , el autor cita la misma palabra con idéntico significado para Colombia, Puerto Rico y Cuba).

No cabe duda de que la palabra americana continúa el esp. ant. ora que no parece sobrevivir en los dialectos españoles actuales, pero que se conoce en Portugal: oura, oira "perturbação da cabeça, produzida por fraqueza ou debilidade", con el verbo ourar, oirar 'ter tonturas de cabeça', aunque estas palabras ya no son muy usuales; pero se usan todavía en los dialectos, p. ej. en la isla de Madera oirar 'entontecer' (CAnuto SoAres, $R L u$, XVII, ${ }_{5} 6$ ).

Estas palabras se derivan, sin duda, del lat. a u r a $(R E W, 788$, donde se cita el port. ourado 'schwindelig', pero no la forma básica, ni la del español antiguo). Parece que a u r a tenía ya en latín el significado de 'locura'; en este significado ocurre en las "tablettes d'exécration", publicadas y comentadas por M. JeAnNeret, Les tableties d'exécration latines, Newchâtel, I9I8, pág. io I (véase Franz v. Wartburg, Etymol. Wörterbuch, I, pág. I78), y en el lenguaje médico de España e Italia aura se usa en el sentido de 'sensación nerviosa como de.vapor'; "la sensazione patologica di una corrente d'aria calda che dal corpo salga alla testa; ogni sensazione illusoria che si produce nelle crisi nervose, e specie i sintomi che precedono le crisi epilettiche e isteriche" (FERNANDo Palazzr, Novissimo dizionario della lingua italiana, Milano, 1939, s.v. $)^{1}$.

El diccionario colombiano de Tascón contiene además el adjetivo horático 'epiléptico' (pág. I 70), mientras en otros países de Centro América orático tiene el sentido de 'venático, ideático' (Malaret, Dicc.

${ }^{1}$ Es del todo inadmisible la idea de J. BRÜCH ( $Z R P h, \mathrm{XXXV}$, IgI2, pág. $578)$, quien, sin curarse ni en lo más mínimo de las otras palabras afines, ni de la historia de la palabra, quiere derivar el port. ourar de un visigótico * a u 2 a $\mathrm{n}$ 'estar vacío', pasando por una forma hipotética * o u a r, de la cual no se ve la razón. 
de americ., pág. 6oo); 'venático, medio loco' (Membreño, Hondureñismos, 3a. ed., pág. I 2 I ).

Este adjetivo no se conoce, en esta forma, en la Península; existe, sin embargo, orate 'loco, demente'. Covarrubias dice en su Diccionario: "orate, vel horate 'el loco que tiene horas y dilucidos intervalos', de ho r a". Pero H. R. Lang, Spanish and Portuguese orate, en $R R Q$, III, 1912, págs. 310-312, probó definitivamente que el esp. orate corresponde al catalán ant. orat (prov. aurat), de la misma base que ora, oura. La procedencia del catalán se explica por el hecho de que el primer hospital de alienados de la Península fué fundado en Valencia en I 409 ("Casa dels Inocents de Valencia"), y el segundo en Zaragoza en 1425, llamado "Casa de Orates". En portugués tenemos orate o zorate y zorato (las últimas dos formas, las da Cândido de Figueiredo como formas provinciales, y así se lee en la Estrada de Santiago de AQuilino Ribeiro, pág. 293: "encarceraramno numa cidade como vadio, noutra como zorato". La forma zorate se debe a una separación errónea en la conexión casa dos orates, como ya indicó LEITE DE VASconcellos, Lições, 2a. ed., pág. 6i , nota I, y Julio Moreira, Estudos, vol. II, pág. I 3I. Por lo demás, si hoy, por lo común, se dice en español: casa de orates, antiguamente se decía también: casa de los orates (así se lee en Fr. Luis de Granada, Symb., part. 4, trat. 2, cap. 22: "Véase si es posible que el que esto decía lo crea assí: y si dixera mas uno de los que están atados en la casa de los orates", frase citada por el Dicc. de Autoridades).

Es notable también la derivación catalana: exorar, axorar 'perder el juicio, enloquecer' (Dicc. Aguiló, s.v.).

En cuanto al hispanoamericano, es digna de atención la conservación de una palabra española antigua, olvidada en España, arcaísmo que coincide con el de Portugal. La $h$ de hora, horático, que emplean generalmente los lexicógrafos americanos, se debe evidentemente a la conexión, aunque errónea, con hora, que ya indujo a error a Covarrubias. Si, en Colombia ( $h$ ) orático tiene el significado de 'epiléptico', esto se debe al sentido que $(h)$ ora asumió en Centro América; pero el significado verdadero es sin duda el de 'demente', ya que orático procede del esp. orate, con el sufijo -ático, que de maniático, lunático, etc., pasó a otras formaciones que envuelven la idea de 'loco', como temático, ideático, venático y otros aducidos en $\mathrm{mi}$ artículo sobre este sufijo en Iberoromanische Suffixstudien (ZRPh, LXIV, 1944, págs. 36r-362) ${ }^{2}$.

Max Leopold Wagner

Universidade de Coimbra.

2 En REW, 788: aura figura, como es debido, el catalán orat ( $>$ esp., port. orate) y el port. ourado, pero en el no. $608 \mathrm{r}$ : orare, se cita otra vez orate, con remisión al artículo de Lang y a las Lições de Leite. Ahora bien, ninguno de los dos autores se pronuncia en favor de orare; por el contrario, Lang rechaza expresamente la suposición de W. I. Krapp (ed. de E. P. Bazán, Pascual López, Boston, 1905, pág. 207), según el cual orate sería el imperativo latino 'pray, beg' 